\title{
In a broken world: towards an ethics of repair in the Anthropocene
}

Duncan P. McLaren (d.mclaren@lancaster.ac.uk)

Forthcoming in Anthropocene Review

Author's Accepted Manuscript - for personal use only - February 2018

\begin{abstract}
With the power to break earth systems comes responsibility to care for them, and arguably to repair them. Climate geoengineering is one possible approach. But repair is under-researched and underspecified in this context. In a first attempt to establish basic principles for the obligations of repair in the Anthropocene, five disciplines of repair are briefly reviewed: reconstruction of historic buildings, remediation of human bodies, restoration of ecosystems; reconfiguration of cultural materials and artifacts; and reconciliation of broken relationships. In each case ethical practices and debates are described to help identify key themes and challenges in understanding repair. Three interlinked pragmatic ethics or virtues of repair in the Anthropocene are suggested: care, integrity, and legibility. Implications of for climate geoengineering, climate politics, and the possibilities of climate justice are explored. Climate repair is defended against objections that it would exacerbate a moral hazard effect, or frame climate responses as politically conservative.
\end{abstract}

\section{Keywords}

Repair, Ethics, Justice, Geoengineering, Care, Anthropocene 


\section{Introduction}

Both materially and discursively, the Anthropocene is redefining humanity's relationship to the Earth, positioning humans not only as a dominant impact on climate and environment, but also as vulnerable to the agency of earth systems. Anthropocene discourses break down distinctions between humans and nature and legitimate efforts at planetary management, but also arguably obscure human inequality and diversity (Crutzen \& Schwägerl 2011, Baskin 2015, Moore 2016). Climatically, the Anthropocene can be characterized as an epoch of instability triggered by human activity, in contrast to the stable hospitable climate that accompanied the development of civilization (Steffen et al 2011). Dramatic changes such as the loss of major ice-sheets now seem inevitable, and reversing such impacts would require a much more extreme reversal in climate conditions and temperatures (Lenton et al 2008).

It is in this context that the climate system becomes symbolic of a broken world (Jackson, 2014): seriously disrupted, certainly vulnerable to further drastic change, maybe on the brink of a devastating collapse, and moreover, apparently impossible to perfectly restore. In the Anthropocene, arguably, with the power to break earth systems comes the responsibility to care for - and even repair - them. Attempting to repair the climate system through geoengineering is one possible response. Yet Anthropocene discourses also tend to frame humanity as a single entity, and potentially deflect attention from questions of justice and radical politics. From such a perspective, climate geoengineering arguably promises the power to sustain industrial capitalism in the face of otherwise disruptive climate change.

This paper seeks to understand what climate repair might mean in the Anthropocene. It first reviews ways in which proponents and critics of climate geoengineering have engaged with ideas of repair, suggesting that these are typically simplistic and that more sophisticated approaches are desirable. It then proceeds by examining five different disciplines covering the broad territory of repair, where experience with, and debate regarding, repair is rich and long-standing. The aim is to surface and learn from ongoing debates rooted in embodied practice, not to essentialize the virtues revealed or to claim that they are necessarily transferable. The disciplines chosen are not necessarily direct analogues for climate geoengineering, but offer insights into ways in which repair is conceived and how such conceptions are changing in the Anthropocene. The paper then briefly applies these insights to climate geoengineering, seeking to stimulate more reflexivity in debate and practice. It concludes by outlining a initial proposal for the virtues of repair in the Anthropocene, based on the interlinked principles of care, integrity and legibility which emerge from analysis of the five arenas. 


\section{Climate geoengineering as repair}

Climate geoengineering is typically understood as large scale, intentional, technological intervention in the processes driving climate change (Royal Society 2009; NAS 2015a\&b). With its connotations of control over the entire climate system, climate geoengineering is arguably the signature Anthropocene technology. It includes both techniques to directly reduce net heating (solar radiation management or SRM) and to reduce greenhouse gas concentrations in the atmosphere (carbon dioxide removal or CDR). CDR approaches are slow-acting, and their practice at planetary scale threatens to disrupt other aspects of the earth system and human society particularly through demands for biomass (McLaren 2012). SRM approaches are typically considered to be relatively low cost, and high leverage, if also of higher risk than CDR. Moreover SRM would actually generate novel climates - especially in terms of precipitation regimes - even if global average temperatures were returned to preindustrial levels (McLaren, forthcoming). Even in the absence of climate tipping points, climate repair through geoengineering would therefore be at best partial and incomplete.

Despite such limitations, metaphors of the planet as patient or as machine in need of fixing dominated climate geoengineering discourses for many years (Nerlich and Jaspal, 2012; Loukkanen et al 2013). And as interest grew, some advocates sought deliberately to shift the discourse. One leading SRM scientist has argued that "Geo-engineering is an absolutely terrible word ... [with] connotations of Dr. Strangelove ... in fact, it should be called something like climate restoration" (Latham, cited in Kanchwala, 2012), while the chair of the Arctic Methane Emergency Group (the only scientists already calling for deployment of SRM) has said: "Politically, I think "restoration" has the better connotations and sounds more valuable” (Nissen, 2008). Others have suggested “analogs in 'forest restoration', 'art restoration', and 'building restoration"' and advocated treating 'climate restoration' similarly as a form of "return of something to a former state through (intentional) action” (Alano, 2008). In a similar spirit, the Bipartisan Policy Center (2011) sought to redefine geoengineering as 'climate remediation' (despite some of their high profile taskforce members actively dissociating themselves from this particular suggestion).

Such ideas remain pervasive in geoengineering discourses. Biological CDR techniques such as afforestation and regenerative grazing and biochar, and even controversial ocean fertilization are discussed in terms of soil, land, habitat or species restoration (Lal, 2004; Nelleman et al, 2009; McLaren, 2012; Tollefson, 2013; Thomas and Gale, 2015). And much contemporary SRM modelling work remains focused on designing potential interventions which best 'restore' pre-industrial climates and minimize infidelity to historic climate states (McLaren forthcoming). 
While technical and managerial metaphors such as those of restoration or remediation are widely used to support climate geoengineering (McLaren, 2016a), the idea that the earth could be 'fixed' as if it were an artefact that could be reconstructed is also often challenged. 'Fixing' is also often used pejoratively, evoking concern over the idea of a 'technical fix (Fleming 2010; Markusson et al 2017). Fleming argues in 'Fixing the Sky' (2010) that the history of often fraudulent claims for weather modification offers clear warning against the misuse and hubris implied in such terminology. And reflecting a wider concern, activist Naomi Klein argues, "the solution to global warming is not to fix the world, it is to fix ourselves" (2014: 279).

Although such discursive battles did not change the terminology used in climate geoengineering discourse, the underlying beliefs amongst advocates for redefining the concept as remediation or restoration do not appear to have changed. In this paper I advance the view that a more considered analysis of the implications of ideas of repair could be helpful in promoting a more discriminating and politically aware assessment of both the broad concept of climate geoengineering, and of its various possible forms, in the discursive and material context of the Anthropocene.

Concepts such as restoration, remediation and repair imply certain connotations and presumptions. In particular these terms - in English at least - tend to suggest visual, functional, and historical fidelity - a suggestion that a good repair will lead to the repaired object looking, and performing in the way it did before the damage occurred. A repaired window will let in light and keep out the weather, for instance. A healed broken leg will look like it did before, and permit its owner to walk, run and jump as they did before. Discourses of climate restoration or remediation then evoke these mental models, implying an ability to restore the functionality and appearance of some prior climate state (despite the inherent limitations of climate geoengineering in this respect). Yet ethically, to focus only on function would appear simplistic and utilitarian at best, incomplete and misleading at worst.

In contrast, here I treat repair as inherently a political and moral intervention in the world, with multiple dimensions (Graham and Thrift, 2007; Verbeek, 2011; Cotton, 2014; Jackson, 2014). Repair is an integral part of the co-production processes by which humans engage with both the past, and the future (Groves, 2014). By implication particular repairs are morally evaluable as better or worse, permissible or impermissible. Yet mainstream ethical theories typically struggle to offer clear guidance for the uncertain futures of the Anthropocene (Groves, 2014). Rather than starting from a particular (universal) ethical stance, I recognize ethics as a contested and negotiated space, structured by biological and cultural evolution (Fitzpatrick, 2014; Held 2006). In my efforts to identify and codify common 'ethics of repair' in a pluralist ethical framework, I 
therefore adopt a pragmatic approach, iterating between a descriptive elicitation of ethics from behaviours and practices (Minteer and Manning, 1999), and an evaluative assessment (rooted in Sayer's critical realism (2008)), which locates ethics in human values. In a practical sense therefore, repair has 'pragmatic ethics' or virtues - morally desirable values and characteristics, rooted in collective social and cultural understanding.

The pragmatic, empirical approach does not imply a descent into cultural relativism leaving no possibility of assessing practices or positions against an ethical benchmark. The practical ethics emerging in climate engineering can still be compared with and assessed against those from other disciplines or cultures. In this paper I seek to identify robust contemporary virtues of repair by examining practices in older disciplines where the ethics are - arguably - more mature. I am particularly concerned to identify commonalities in how the objects (or subjects) of repair are conceived, what agency those subjects are understood to exercise, and what forms of fidelity to past states are considered appropriate. I also highlight current debates over ideas of repair which appear relevant to, or stimulated by, the onset of the Anthropocene, in particular those relating to the potential for the repairer to exercise control over the subject of repair.

Such considerations open important questions for debate. What might framing climate geoengineering as repair reveal about the nature of the practice, who might undertake it, and why? If it is a form of repair, what is the subject of repair, and what forms of fidelity to the original might matter? For example would a 'good' climate restoration exhibit fidelity of appearance, function or process, or fidelity to a particular historic state? Would a focus on repair detract from or reinforce efforts to achieve climate justice? Could such a process of repair be politically transformative, or merely sustaining? In this paper I explore such questions, with a focus on the issue of which virtues should guide efforts at repair or restoration.

\section{Diverse conceptions of repair}

To identify salient values I review here a range of disciplines of repair with long histories, and active debate amongst practitioners and experts as to the relevant ethics of the discipline. Climate geoengineering researchers have already drawn analogies with restoration, remediation and other forms of repair. Here, extending and modifying a categorization based on Sennett (2013) I briefly examine reconstruction (of historic heritage); remediation (of human bodies); restoration (of ecosystems); and also reconciliation (of relationships) and reconfiguration (of cultural artifacts). In each case the treatment is necessarily simplified, and cultural variations in ethics left unexplored, in the interests of tracing out the significance of three virtues emergent in the current discourses of 
these disciplines: care, integrity and legibility, and highlighting relevant implications. Care implies an attachment to and respect for the subject as an agent in itself. Integrity suggests a goal of selfdirected functioning and healthy process. Legibility implies a repair process that is transparent, honest and not hidden.

\section{Heritage reconstruction}

This section draws on expert and practitioner experience with material artifacts, particularly buildings, of historic interest and value. In many countries, and internationally, valued historic heritage is protected, and appropriate rules, standards and ethical practices for interventions, including repair and reconstruction, are debated amongst professionals and interested publics. Heritage reconstruction is of relevance to the Anthropocene climate challenge because, inter alia, like the climate case it seems to reflect people's desires to recover a past state of greater functional value to humanity, in the face of deterioration which seems to require active intervention. In heritage conservation the need for repair is more often a response to natural decay of artifacts whose functions have become redundant, than to direct or indirect anthropogenic harms, yet both are the result of similar economic and cultural transformations.

At first glance, the reconstruction of historic heritage might seem to exhibit the goal of fidelity or authenticity to some pre-existing state. However, even within the dominant ethic of 'preservation', simplistic ideas of visual fidelity have long been rejected, in favour of non-intrusive maintenance and reversible and 'legible' or 'transparent' repair - in normal circumstances (Burman, 1995). Large scale reconstruction (in line with historic records) is understood to be only clearly justified in cases of deliberate damage or war - such as the new 'old bridge' at Mostar in Bosnia, or the historic core of Warsaw, reconstructed after World War 2. Large scale reconstruction for aesthetic and economic reasons, for example at Carcassonne in France, is typically criticized as inauthentic and intrusive (Cameron, 2008). The Mostar and Warsaw reconstructions have both been recently listed as World Heritage Sites, though more for their cultural importance in providing memorials of those conflicts (a sort of 'narrative fidelity' of place), than for their material or historic fidelity (Cameron, 2008). In such cases the 'legibility' of the repair remains important, albeit resting more in the documentation than the physical form. At the opposite extreme DeSilvey (2017) discusses cases of 'curated decay' in which natural deterioration is documented rather than halted, as a means of providing a similar memorial function in different ways, while recognizing the agency of the linked material and natural systems as 'ecofacts' rather than artifacts.

For more contemporary artifacts, one might assume that functionality is all that matters, but in repair and mending scholars such as Jackson (2014) and Middleton (2014) reveal emerging 
pragmatic ethics in which repair reflects attachment (and values of sustainability as opposed to consumerism) rather than simple need and functionality - repaired clothes are returning to fashion, repair cafes are spreading around the world. Mending is becoming visible, rather than invisible. The process of repairing is perhaps even being recognized as a character building virtue, rather than an activity to be hidden away, and left to (or imposed on) marginalized groups in society.

Even though the analogy between designed artifacts and the climate is far from perfect, there are interesting lessons already here. The justification for reconstructive approaches in cases of deliberate damage - such as in wartime - might imply a similar justification for climate repair through geoengineering, but this justification would appear weak if the reason for geoengineering were instead to maintain economic interests which might be threatened by the alternative of accelerated mitigation. More generally, even though current people may be able to identify the intentions and purposes of the original builders and designers, ethical repair of historical artifacts involves something more (and in some respects, deliberately less) than functionally, materially and visually faithful reconstruction. In part that reflects an ethical respect for the artifact itself and its history and narrative and an understanding that the morality of things is in important ways coproduced between designers, users and the things themselves (Verbeek, 2011; Sennett, 2013; Cotton, 2014). Yet the agency of artifacts is still limited, and often unrecognized.

Next I consider a sphere in which the agency of the subjects concerned is generally clear and accepted: repair of human bodies.

\section{Medical remediation}

The focus of remediation is on restoring function through healing and medicine. In mainstream medicine the key ethics are to 'first do no harm, to act in the best interests of the patient, to respect their autonomy and to allocate treatment resources fairly (Beauchamp and Childress, 2008). With human subjects, as opposed to inanimate artifacts, the ethical goal is clearly to recover integrity, autonomy and agency. Medical ethics recommend interventions that (as far as possible) support the subjects' bodies to heal themselves.

Human bodies may seem a poor analogue for the Anthropocene climate, and there are substantial practical differences. But medicine offers profound insights into how we respond when agency in the subject is recognized (and the Anthropocene arguably demands that we recognize the agency of earth systems as much as the human agency to change them (Clark 2011)). A central debate in medicine addresses the extent to which contemporary practice dehumanizes patients, treating 
them as objects. As a result, medicine is one of the arenas in which a feminist ethic of care has emerged to promote a focus on the individual as a relational human agent, their needs and vulnerabilities, on the solidarity and attachment between carers and patients (helping patients become agents), and to challenge the medicalization of health systems and their relative domination by interventionist medicine (Gilligan, 1982; Tronto, 1994; Held, 2006). The ethics of care seek to treat the subject as an active participant in the healing process, as well as an individual whose consent is demanded.

In remediation, the dominant ethic with respect to appearance is one of invisible mending. We don't want surgeons to leave us with unsightly scars any more than we want impaired function. Nonetheless, there are debates about the role and appropriateness of legibility as opposed to invisibility, especially where natural healing is impossible, and surgical reconstruction is an option. Ideas of legibility appear in diverse forms - typically secondary to function - such as tattoos over surgery sites, or artistic prosthetics (Eveleth, 2015a,b). This can be seen as a demand for a form of recognition of identity (Fraser and Honneth, 2003), similar in some ways to demands for recognition from subaltern groups expressed through movements such as gay pride. In both cases legibility enables open expression of participants' identities and narratives (Galinsky et al, 2003) and again indicates the significance of narrative fidelity.

New technology also raises issues in medical ethics: notably the prospect of enhancement (as opposed to remediation), a development with direct parallels for climate geoengineering, with its apparent potential for 'designer climates' in the Anthropocene. Human enhancement exposes deep uneasiness amongst both publics and medical practitioners, with profound contestation over the use of drugs, medical implants and gene therapies which step over a boundary from repair to enhancement. For instance, use of memory enhancing drugs to combat senility is seen as right and proper, but not to help healthy teenagers cram for exams (Reiner, 2010). Human enhancement is another front line of the Anthropocene: Promethean versions of the discourse welcome such opportunities, while more skeptical approaches fear the hubris and inequality implied by such technological change (Juengst and Moseley, 2016).

Again the analogy is imperfect, but medical remediation highlights the importance of agency and autonomy for the subject, the risks of dominating paternalism, the significance of narrative fidelity and the differences between repair and enhancement. While the climate system itself cannot be consulted about geoengineering interventions, other stakeholders might be, and the design of any intervention could helpfully take account of the risks of human hubris and domination, beginning by recognizing that any use of SRM would likely need to be continued until underlying greenhouse 
gas concentrations had been reduced by other means. Next I examine a perhaps closer parallel in which the subject - while living and clearly enjoying substantial agency - cannot be directly consulted: ecosystem restoration.

\section{Ecosystem restoration}

Ecological conservation and management has a long history, but in recent years ideas of ecosystem reconstruction and rewilding have become much more widely discussed and attempted, in part as a response to the additional impacts of climate change (Higgs, 2012; Sandler, 2012; Light, 2012; Monbiot, 2013).

On the surface ecosystem restoration offers a strong analogy for climate repair. The subject is a system, with some independent agency, restoration is needed because it has been damaged as a side-effect of economic and social activities that serve human needs and aspirations, and the repaired system itself may also serve some broader function for humanity. Yet, once again, functional restoration is only a part of the ethical practice of ecosystem management in the face of breakage or damage.

Ethical debate in this discipline often focuses on the implications of the impracticality or arbitrariness of choosing any particular baseline state to which to restore; and on the associated risks of humanity dominating by determining the nature and purposes of the restored ecosystems and their species. Some scholars and practitioners see in this a denaturing of the ecosystems concerned, either in terms of the loss of something integral to their nature; or their conversion to an artifact; or both (Katz 2002, Hettinger, 2012). Higgs (2003, 2012) argues a case for simultaneously supporting ecosystem integrity, historical fidelity to place, and intentional human participation (recognizing humans as part of ecosystems, but resisting the hubris of domination). Others, such as Marris (2011) see no practical or ethical problem in such artifactualization.

More generally, ecologists and ethicists appear to concur that humanity has obligations to repair damaged ecosystems (Light, 2012; Basl, 2010; Lee et al, 2014). But repair also risks a form of moral hazard, insofar as promises of restoration can be used to justify destruction of ecosystems for economic purposes (based on unenforceable promises of subsequent restoration). In this situation repair potentially becomes utilitarian; which threatens to devalue impacts felt by unrecognised groups such as indigenous people, future people or non-human species; and generates limited pressure to rectify historic wrongs, or to prevent future risks. In the climate context, it would seem vulnerable to the same problems of moral corruption that have slowed mitigation (Gardiner, 2006), 
while also risking enabling arguments to be made for SRM on the grounds of reduced cost (once an economic metric is accepted).

But repair can alternatively be justified as a process that reverses harms done, or respects ecosystem rights. This permits a clearer focus on the integrity and agency of the system. As with remediation, the restoration of self-directed functioning and active (ecosystem) processes appears most important here, rather than return to a particular baseline or appearance. For instance, the return of wolves in rewilding efforts is more significant for the ecological role the predator plays, than for the specific species itself. And as with healing, legibility appears as a secondary but potentially valuable ethic, not just as an active reminder of our power, but also as a faithful part of the narrative (of place in this case (Higgs, 2003; 2012)) that underpins our identities. In the absence of a clear historic baseline, other ethics come to the fore, in place of historic or visual fidelity, including greater respect for the cultural values and narratives associated with the subject (perhaps, as with heritage above, as forms of memorial, rather than preservation). In some ways the subject of repair is also a relational cultural or socio-ecological system extending beyond the physical boundaries of the habitat concerned. Next in this rapid survey, I turn to a form of repair where cultural values are central: artistic reconfiguration.

\section{Artistic reconfiguration}

Reconfiguration is categorised as a particular form of repair by Sennett (2013), one that not only recovers but enhances function with a mix of existing and new elements. The relevance to climate repair might seem limited, but the climate is of profound cultural importance, and indeed can be understood as fundamentally a cultural, rather than natural artifact (Hulme 2017), even before the Anthropocene. In this respect the subject of 'repair' is a linked cultural-physical-environmental system - involving both the physical objects concerned, but also the relationships and attachments between them and humans. And while artistic understandings of reconfiguration move even further from fidelity to some pre-existing state, this does not mean that 'anything goes'. Artistic work is still guided by socially determined ethics, which, amongst other things, value art for its intrinsic expression of humanity, rather than for its commercial worth.

Historic reconstruction can blur into artistic reconfiguration. In the Japanese art of Kintsugi, for example, damaged pottery is repaired with a gold coloured cement - arguably enhancing the beauty of the artifact by marking the lines of repair and highlighting the history of the object in a sort of 'narrative fidelity'. Understanding the cultural value of the subject is central to this form of repair. Similarly, the war-damaged Neues Museum in Berlin was reconstructed with a mix of historic and contemporary materials, making the story of the damage and repair highly visible 
(Sennett 2013). The result directly illustrates the conservation ethics that inform the management of the museum's collection of antiquities, as well as its structure. Reconfiguration thus bridges repair and making, and blends the roles of artisan and artist (Galarraga and Szerszynski, 2012).

In this context - and remembering that SRM would create novel climates, rather than simply restoring previous states - artistic reconfiguration in domains where repair is a minor aspect of the artist's goal may also offer useful lessons. In literature and music, there are long standing traditions of borrowing and reconfiguration, which can be understood as the recovery or rehabilitation of disused cultural material. And insofar as we understand art as a process less of de-novo invention, and more a tradition of cultural borrowing, improvisation, mashing-up and reconfiguration of ancient elements in new forms, then much repair can be seen as artistic. Throop (2012) for example sees improvisation with dramatic and musical analogies as a virtue in ecological restoration.

Such an understanding of art as reconfiguration is not uncontested. Current battles over copyright suggest that a form of fidelity to and preservation of existing artistic creation is valued, but viewed historically, it is the brief era of strict copyright that is the artistic anomaly (Brewin 2012). Author Neil Gaiman explains a similar shift in attitudes to stories, with particular reference to fairy-tales, repeatedly retold and reconfigured over centuries (Gaiman, 2007). Like ecosystems and the climate, such cultural goods are fundamentally common goods (Brewin, 2012). This is not to suggest ignoring the harms that arise where cultural resources are appropriated from subaltern groups without acknowledgement or recompense - for example where white musicians systematically 'borrow' from black musical traditions. Justice as recognition would suggest that artistic borrowing of cultural resources must instead be part of a process that both respects cultural difference and seeks to increase intercultural understanding (Nicholas and Wylie, 2012). By implication the borrowing or expropriation of climatic resources through domination by climate geoengineering would breach such ethical principles.

The idea of respect for sources is perhaps the central ethic of such artistic reconfiguration. In discussing the Neues Museum, Sennett (2013) writes tellingly of a metaphorical dialogue between the restorers, the original builders and the building itself. Reconfiguration emphasizes the cultural dimensions of repair, but at the same time, blurs not just ideas of historic fidelity, but also those of functional fidelity and even integrity, making narrative fidelity and legibility even more critical. For geoengineering, as a process that would reconfigure the climate (as will be seen in the discussion section), these lessons may prove critical. 


\section{Relationship reconciliation}

Finally I consider an even less tangible and more cultural form of repair - reconciliation deployed to repair broken relationships, particularly in the aftermath of violence or crime. The relevance of this should be clear in the light of the understandings above of both ecosystem restoration and artistic reconfiguration as extending to the relations between the material objects and humans who have meaningful, identity-forming attachments to those objects. From this perspective, lessons from repair of relationships can also be applied to climate repair.

Reconciliation is a restorative form of corrective justice, which seeks to reinstate the offender as a functioning member of the community through acknowledgement and forgiveness of their crimes (and treats the perpetrator, the victim and the community as valid stakeholders in the process of repair). Such approaches have been widely used, but none so large-scale and high-profile as South Africa's post-apartheid Truth and Reconciliation Commission (Gade 2013). Such processes are necessarily incomplete and constrained, and cannot be expected to overcome all imbalances of power. Yet in different ways an ethic of legibility and narrative fidelity appears again: central to such processes is a desire to ensure no pretense that the damage was not done. Forgiveness may be accompanied by forgetting, but as with DeSilvey's (2017) challenge to preservation of heritage, the process is managed or curated with care, to deliver an appropriate memorial function.

In this arena there is also a clear principle of humility and restraint: a recognition that we are but human and fallible, and it also reflects a strong ethic of care in the sense of rebuilding the internal ties of community - as the South African concept of Ubuntu suggests: people are not isolated individuals but achieve humanity only through their relations with other people in society (Gade, 2013). In this context, Ubuntu is an ethic of repair focused on the fabric of community and society. It calls for humility and restraint, and a hesitancy to judge and condemn. It suggests building character and demonstrating solidarity, rather than domination.

Ideas of reconciliation and restorative justice are not limited to the global South. Restorative forms of justice are spreading in many countries with novel forms of inter-cultural awareness building, dispute settlement, post-conflict reconciliation, as well as approaches to even criminal offences that focus on generating forgiveness and reconciliation between perpetrators and victims. Considered globally, reconciliation in a climate context might extend to post-colonial relationships, and solidarity and between north and south, rich and poor, human and nature. As Hourdequin (2012) suggests, climate policy that builds solidarity (rooted in accelerated mitigation and climate justice) is more likely to win the necessary global support than climate geoengineering which can be seen rather as domination. 
Reconciliation emphasizes the significance of cultural and local identities - which can be (in part) embedded in particular climate states, and again the significance of care for the subject, and for narrative fidelity in the process of repair. Reconciliation raises particular questions regarding the nature of the subject of repair, which could be highly pertinent for climate repair.

\section{Discussion: climate geoengineering as repair}

There are many questions raised for climate geoengineering by the foregoing consideration of different approaches to repair. Here I wish to focus briefly on two topics that are central to the application of lessons from the five forms considered above: what form or forms of repair climate geoengineering might constitute, and what the goals and subjects of such a repair might be. I then identify and discuss three common virtues that emerge from the above, and conclude the section by considering and seeking to rebut some potential challenges to applying a repair approach to the topic of climate geoengineering.

What sort of repair would climate geoengineering constitute? Narrowly defined it would appear to be primarily reconfiguration. Eli Kintish's term 'hacking the planet' (2010) seems more apposite than 'fixing the sky'. But does this mean that prospective climate geoengineers should apply only the ethics of the artist, and not those of the artisan, healer, restorer or peace-maker? In practice, the climate appears to be more than just a cultural object. In that case, if climate engineering could only be deployed as reconfiguration, does this mean that it should not be deployed at all? Mitigation would appear to far more closely achieve the goals and respect the virtues found in remediation and reconciliation as described above, notably the principle of 'first do no harm'. Moreover, insofar as it would seem to require human behaviour change and character reform rather than purely technical and economic measures, mitigation is potentially a restitutive form of restoration (Basl, 2010). Yet mitigation may no longer be rapid enough to avoid dangerous climate change. It appears that what humanity might value about climate geoengineering is the extent to which it might deliver aspects of restoration, remediation and reconciliation (over human timescales of decades rather than centuries). In this case it is important to consider what ethics or virtues might properly apply to such a prospect.

Framing climate geoengineering as a repair tool might initially appear to imply not only a process of restoring form and function, but also that that it is the climate that is broken. However, the diverse forms of repair considered above highlight the prospect that the appropriate subject of repair might be different: the earth system, ecosystems, society, even relationships. Even if focusing on the climate specifically, what would be the goal? What does a 'return to healthy functioning' 
constitute? As far as the climate itself is concerned the current state might be reasonably understood as 'healthy functioning' for a high carbon world. This has two implications: first, to acknowledge that any meaningful goal may have to be anthropocentric to some degree: a system that also supports human healthy functioning. But second, that the subject of repair must therefore also include the human part of the climate system. Openness about our anthropocentrism must incorporate a willingness to see ourselves as a part of the problem, and a potential subject of repair. But this also needs to be coupled to an understanding that there is not at present a single anthropos, that humanity remains divided, and those mainly responsible for the environmental impacts underlying the Anthropocene are a particular minority of humanity (Baskin, 2015; Moore, 2016). The implications of climate geoengineering as not just a powerful technology, but potentially also a technology of power, shaped and wielded in the interests of particular groups, must also be recognized (McLaren 2017).

In the examples discussed above, it is clear that the question of what goal or state to aim for (often considered in terms of historical fidelity) is endemic. It should also be clear that in the face of uncertainty or even indeterminacy over what is appropriate, and equal uncertainty over whether goals can be predictably achieved, there are better ways to describe the goals of climate repair. They include recognizing the subject of repair as a subject of care and seeking to enhance its functional and procedural integrity, while providing for some form of narrative fidelity or legibility.

In other words, I suggest that three key principles emerge (see table 1):

- Expressing a virtue or ethic of care: which embodies humility about our capacities, and focuses on the subject's specific needs, reflecting our respect for and attachment to it as an agent in itself, rather than an instrumental use purely to meet our needs.

- Seeking an outcome of integrity - in which the subject has recovered self-directed functioning and healthy process, as far as possible, avoiding a process of denaturing or artifactualization by repair.

- Applying practices and procedures that are visible and legible, and do not attempt to misleadingly cover up the repair or the damage done, but expose culpability and complicity and encourage reconciliation.

These virtues of care, integrity and legibility arise in diverse ways in all the disciplines of repair considered above, and together, I suggest, constitute an appropriate 'ethics of repair' for the Anthropocene. This is not to suggest there is a uniform convergence of virtues and principles across all five arenas, nor intended to give an impression of consensus even within the disciplines considered: the ethics of repair are in many respects contested and often culturally specific - for 
instance with respect to the relative importance of fidelity of material, form, process, history and narrative. However in each of these three areas there is more commonality than contestation.

[Table 1 around here]

The following three sub-sections unpack these principles further and discuss how they might apply to climate engineering.

An ethic of care

An ethic of care is expressed in forms of repair and maintenance which are primarily rooted in attachment to the subject (which, as noted previously, may or may not be the climate itself), rather than in functional concerns or even obligations of justice. In some ways this echoes - and extends the Kantian dictum never to use people as means, but always to treat them as ends in themselves. As an ethic, care (Held, 2006; Tronto 1994) respects agency, and can be counterposed to ideas of medicalized treatment, or decisions made on anthropocentric judgments of value. It shows respect for the subject, its dignity and origins, expressed where practical in consent and involvement. Care in repair is closely associated with virtues of humility and restraint, which recognise the limitations of human interventions. Care is particularly strongly expressed in ideas of repair as reconciliation, and this too can be usefully applied to the climate, where arguably the thing most in need of restoration or reconfiguration is not the climate itself, but humanity's exploitative, instrumental relationship with the Earth. Hamilton (2017) similarly positions care as the key responsibility of humanity in the Anthropocene, in contrast to the 'wanton' neglect with which the majority of humanity has treated the Earth in the modern era.

Similar contrasts between an ethic of care; and more technocratic approaches of reconstruction or reconfiguration - rebuilding ancient monuments; enhancing human capabilities with drugs or surgery; or cultivating 'rambunctious gardens' (Marris, 2011) - are found in the context of buildings, health, and ecosystems. This is not a simple dualism, however, but a spectrum. An ethic of care might prioritize the ongoing maintenance of sustainable low-carbon lifestyles, while the technocratic approach is more open to attempted large-scale reconstructive interventions. Yet even grand climate geoengineering interventions might learn something from the ethics of care emergent in other fields or repair: not just about whether to intervene, but when and in what 
forms, and with what governance. For example, proposals to use SRM to retard rates of climate change (Keith 2013) might express care better than those suggested to reverse all warming.

While care recognises individual needs and vulnerabilities it is not purely individual. It is rather inter-subjective and relational. As care, repair can be seen fundamentally as a means of building solidarity within and between societies, and with their supporting environments. In the context of the climate, this implies seeking interventions that work to deliver corrective and restorative forms of climate justice, and moreover, ones that help tackle economic and social inequalities and injustices too. It is hard but not impossible to consider ways in which climate geoengineering interventions could help do this (Buck 2012, Martindale 2015) - particularly in some forms of CDR, such as soil or ecosystem restoration, but all too easy to see approaches - especially to SRM - that reflect a paternalist and technocratic hubris, in which geoengineering 'solutions' sustain existing injustice (McLaren, 2016b).

Care implies humility rather than hubris. Sandler is not alone in dismissing the idea that humanity has the necessary capacity to predict and control, and criticizing climate geoengineering as "again trying to adapt the world to humans, rather than vice versa" (2012: 77). Most climate geoengineering proposals are rooted in social imaginaries of risk management (Groves, 2014) in which technical expertise can be deployed to control risks, rather than focusing on vulnerabilities and means of building capabilities and resilience (McLaren, forthcoming). Such hubris exacerbates the moral hazard of 'restoration' - the idea that the availability of repair mechanisms permits humanity to delay maintenance and mitigation. Our susceptibility to such temptation (Gardiner, 2006) could itself be seen as a behavioral flaw meriting repair. Devising climate geoengineering interventions that effectively exhibit an ethic of care will be challenging in this context.

Integrity

Rather than recovery of a baseline state, many forms of repair seek to achieve a form of authenticity that might best be described as integrity. This is a coherence with the intrinsic functionings and processes, and essential virtues of the subject (as a relational system). It is implied in the respect for sources seen in reconfiguration, and clear in the autonomy and agency sought in medical remediation and ecological restoration. The pursuit of integrity means repair that helps the subject recover self-directed functioning and healthy processes. On the other hand repair processes which dominate the subject, impose external visions of reconstruction or enhancement, or act to denature it by converting it from a natural system to an artifact are all seen as ethically deficient in their relevant fields. 
The key challenge of integrity for climate geoengineering is whether it effectively removes agency from the climate system, turning it into little more than an artifact. Sandler (2012) argues that simply because restoration requires design, restoration reduces ecosystem agency: design is inescapably anthropocentric in this view. Galarraga and Szersyznski (2012) similarly suggest that with SRM “For the first time we would have a made climate" (p221). Intentionality appears central to such an understanding of 'made-ness' (in contrast to climates made unintentionally by the effects of widespread agriculture and forestry (Ruddiman et al 2014), or in cultural ways (Hulme 2017)). However made-ness would seem to equally incorporate some notion of effectiveness, which is far from certain in climate geoengineering (Stilgoe, 2015). If humanity could not in any sense obtain outcomes that reflected its designs or intentions, then the production of the new climate would be less 'making' and more a process of accident, or 'emergence'. Moreover, the effect of climate geoengineering may be to simultaneously constrain the agency of the climate, and increase the power of humanity, but it would not extinguish climate agency: earth systems could be expected to remain recalcitrant or defiant (Hamilton, 2017).

Given the cultural significance of climate, it would remain ethically problematic even if the relative denaturing of the climate were only discursive, rather than physical. Nerlich and Jaspal (2012) highlight how the linguistic emphasis on 'fixing' the climate drives a metaphorical transformation of the climate into an object that needs repair, using a technological toolbox (or a body needing treatment with a medical toolkit). Such discursive framing underpins Anthropocene discourses such as that of the 'Rambunctious Garden' (Marris, 2011) which treat such interventions as normal and appropriate, implying, for example that human choices would (and perhaps should) structure the species mix and management techniques applied to ecological systems (as they do in gardens). Keith similarly highlights past change in ecosystems as validating continued intervention, "in part, their value lies in the history of how they got the way they are, the co-evolution of nature, culture, and technology" (2013 p.xviii).

Even if the climate system could be structured through such intervention, and however inevitable it might appear, such thinking justifies anthropocentric domination and de facto denaturing. The integrity principle is clearly being ignored in such circumstances. On the other hand, once the climate is recognized as more than an artifact, the integrity principle helps one to conceive it meaningfully as a relational system with agency, or at least an autonomous status, which merits human care. 
Legibility and narrative fidelity

The third and last common principle is that of legibility. This demands repair practices that are transparent and leave a visual trace that - at least to an expert eye - effectively inscribe the repair into the narrative or history of the subject. This clearly appears in reconstruction, remediation and in ecological restoration. It is also inherent in reconciliation, where the mending process typically demands open acknowledgement of the damage by the perpetrator and the requesting and granting of forgiveness for it from the victim; and in the demands for respect for sources in reconfiguration. In some cases legibility also supports or enables reversibility of the process (as in heritage reconstruction). In this usage, legibility does not necessarily imply controllability or simplification (as it does in the work of Scott, 1999), and thus challenges, rather than reinforces existing power relations.

In the foregoing I have associated legibility with the idea of narrative fidelity on the basis that - in contrast to efforts at invisible mending - an honest and faithful narrative or history of the subject must include a record of its damage and repair. Narratives not only support the continuity of places but also underpin human identities. This one of the reasons place-based restoration of heritage and ecosystems is so intensely scrutinized and its qualities contested. The reconstruction of Mostar and Warsaw (and their listing as World Heritage) was arguably driven by a "deep-seated desire to resurrect identity" albeit in the exceptional circumstances of "deliberate destruction of cultural resources through war" (Cameron, 2008: 23). Questions of culture and values would be challenged by 'climate restoration' in the same ways as by the reconstruction of the Mostar bridge, or the reintroduction of the wolf in rewilding efforts. Repair is never simply about technical questions of function and material performance.

In many cases - and the climate would be one - the ethical case for legibility is not just rooted in the honest record of the object's history, but in the memorial it creates regarding the cause of the damage. In this respect the transparent reconfiguration of the Neues Museum is arguably more valuable than the reconstructions at Warsaw and Mostar, where the memory resides in the listing and its documentation, rather than the physical form. There is an intriguing parallel here for SRM climate engineering. The most widely discussed form: stratospheric aerosol injection (SAI) would leave two visible traces - it would whiten skies, and redden sunsets. In the conception of ethical reconfiguration I have set out here, these visible marks - even if aesthetically pleasing - should be understood and valued as a reminder not only of the damage humans have done to the climate, but of the ongoing negative side effects of SAI which include slowing ozone recovery. They would potentially provide a constant stimulus to enhance our efforts to accelerate mitigation and bring 
SAI to an end. Yet some geoengineering researchers are considering not only how to design particles with fewer side-effects, but ones with negligible light-scattering effects, which would eliminate the legibility of the repair (Keith, 2013).

Such efforts would turn climate repair into yet another element of the invisible maintenance and repair that constitutes a hidden shadow to neoliberal industrial capitalism. The modern world is arguably much more dependent on maintenance and repair than on innovation and invention, yet the latter are lauded, and the former concealed (Jackson, 2014). As an ethic for the Anthropocene, legibility of repair seems essential. In an era where repair is unavoidable as a result of the accumulated impacts of humanity on the earth and its systems, it is critical to bring repair out of the shadows: it cannot remain a discipline delegated to subordinates and minorities, nor can its aesthetic remain that of invisible mending. Both the processes and outcomes of repair should be visible and legible if it is to be practised ethically.

Some challenges to a repair approach

Before drawing conclusions I want to discuss two challenges that might be legitimately raised to applying ideas of climate repair to geoengineering. Firstly that it risks discursively and inappropriately framing the climate as an object amenable to human intervention and in so doing risks magnifying the moral hazard associated with climate geoengineering. And secondly that it frames appropriate interventions as politically conservative (rather than radical, or transformative), a criticism that fits within a wider critique of the Anthropocene discourse as distracting attention from political questions of injustice.

The first risk is real, but derives mainly from misunderstandings of repair in popular discourse. More systematic analysis, such as that set out in this paper, reveals that ideas of repair need not embody hubris regarding human control, but to the contrary, repair practices often reflect a concern for the agency and autonomy of the subject. But in the absence of such humility, the risk of moral hazard should be recognized. The more it appears that climate geoengineering could 'repair' a damaged climate, the easier it may be for businesses and politicians to justify continuing emissions, especially given the ways in which geoengineering potentially underpins existing relations of power under neoliberalism (McLaren 2017). The lack of historic or functional fidelity of repair by SRM geoengineering (which would not reverse ocean acidification for example) means that moral hazard has to be taken seriously, even if substituting it for mitigation would be irrational (McLaren 2016b). However, our review above demonstrated that historic fidelity is a challenge in most forms of repair, that neither historic nor functional fidelity need be perfect for repair to be 
valued, and that other forms of fidelity should be considered also. So the moral hazard problem while serious - does not invalidate considering ideas of repair.

It is also reasonable to note a broad association between repair and conservative political views. Again however, this is rooted in the common perception of repair as advocating a (politically conservative, or nostalgic) longing to return to some historically previous state, or as sustaining the status quo; rather than embodying a progressive or radical future-oriented stance. This problem is reinforced by framings of the Anthropocene that falsely or at least prematurely unify humanity into a single entity (Moore, 2016). These frame out questions of justice, and radical political solutions. The analysis above suggests that treatments of repair in mainstream scientific discourses of climate geoengineering might indeed mobilize it as a conservative, sustaining technology, deployed to enable a gradual transition of eco-modernization, or even harnessed to a neo-liberal libertarian promethean agenda (McLaren, 2016a).

Once again a more sophisticated understanding of repair indicates ways in which ethical repair could challenge such framings. Once the subject of repair - broadly understood - is recognized as an active agent, and participant in the process of repair, the politics of repair is potentially upended. If the interests and perspectives of post-colonial or subaltern communities in the global South (the primary victims of climate injustice) become heard and counted in a reparative process of reconciliation, it even holds out the prospect of a moment of genuine politics and a transformation of power relations (Rancière 2004). And if the interests and perspectives of the climate system or indeed of the technologies involved in repair activities can be voiced, then such a moment may even extend (contra to Rancière) beyond the human. Further, the focus of integrity and legibility on a respect for situated narratives of place and identity necessarily rejects the universalist and paternalist treatment implied in eco-modernization and promethean framings.

Radical approaches might particularly suggest exploring lessons from reconfiguration, but also the ways in which reconciliation and repair might heal divisions, including through genuine restorative justice, as long as such obligations of repair are understood not as a general universal duty on humanity, but primarily as a duty on those responsible for historic and ongoing division, harm, and breaches of rights.

Moreover, while care is often counterposed to justice in ethical terms, and repair might be similarly framed, the ethics suggested above would rather strengthen the prospects for climate justice, understood through a lens of justice as recognition (Fraser and Honneth, 2003; Schlosberg, 2007). Recognition theorists in moral philosophy argue that justice depends upon full and proper recognition of each individual and their identity, enabling fair treatment, appropriate redistribution 
and the development of essential capabilities (Fraser and Honneth, 2003). Environmental justice scholars highlight the importance of respecting community and movement based demands for recognition of identity, difference and interests (Schlosberg, 2007; Walker, 2012). Understood in these ways recognition underlies all three of the identified ethics (care, legibility, and integrity). Care for the specific subject is based in recognition of the subject and their agency, requiring the practitioner of repair to see the actual subject, not just its condition. Integrity relies upon the recognition of difference, and thus seeking to restore the essential nature of the subject, rather than paternalistically projecting the repairer's ideals. Legibility implies revealing the narrative of identity of the subject, which in turn is central to recognition (as in history of slavery for instance). These may stretch ideas of recognition beyond conventional applications in moral philosophy, but not beyond the ways in which recognition is applied, and demanded, in movement-based politics and environmental justice scholarship (Schlosberg, 2007).

Disaggregating and unpacking ideas of repair - and particularly the virtues expressed in real-world practices of repair - thus offers new ways to engage with and enrich our climate policy options in the face of the uncertain, and broken futures of the Anthropocene. Caring both for the climate, and the human communities that depend upon it physically and culturally. Recognising the essential and inter-related natures of climate and earth-human systems, and seeking to restore their integrity. Approaching repair and reconfiguration with humility not hubris, carefully marking the traces of human interventions. And seeking restorative justice based in recognition and reconciliation.

\section{Conclusions}

I have argued that a sophisticated understanding of repair reveals valuable virtue ethics that could guide human interventions in earth systems in the Anthropocene. While understanding the Anthropocene implies accepting inevitable anthropocentricity in both how humans understand and impact on the world, it also implies retreating from the sort of anthropocentricity that puts human goals at the center of the Earth system. That would lead to 'denaturing' the climate in both senses of the term: changing its essence, and extracting its 'natural' aspects. This is not to suggest that the climate today is some independent wholly natural object, rather that it is a linked cultural-natural system, relationally incorporating humanity through our attachments to it (Hulme, 2017, Groves 2014). Moreover its essence includes some independent agency to the extent that it may be appropriately considered as a rights-bearer independent of its human components. 
In engaging with such a subject of repair, I have argued that potential climate geoengineers need to learn from other disciplines, and apply virtues of care, integrity and legibility. This does not mean abandoning ideas of fidelity in repair, but - recognising the impracticality of entirely reconstructing the climate, it focuses our aims on fidelity of function, process and narrative in reconfigurative forms of repair, not narrowly on form and history (which are notably often western cultural tendencies). With respect to climate policy, these virtues reinforce arguments that accelerated mitigation and adaptation are preferable responses, but they could also help guide the procedures, aims, practices and governance of climate geoengineering should it be considered an essential complementary climate measure. Future work could usefully probe further into the diversity of culturally specific conceptions of repair and restoration to help improve the methodologies of pragmatic ethics, strengthen the empirical foundations of the virtues described here, and to help design ethical and just responses to climate change. Further research could also usefully unpack the relationships between climate geoengineering and existing regimes of knowledge, interests and power relations.

For instance, it must be acknowledged that the breaking of the climate system can no longer be seen as an accident: people know what greenhouse gases are doing to the climate, yet most refuse or are unable - to cut emissions as quickly as they could. Intentionality would seem to convert obligations to repair through reconfiguration also into obligations of reconciliation, with the earth and its diverse peoples and species. Yet the idea of reconciliation carries a further meaning worth reflecting upon: not just rebuilding community, but also being reconciled to transience and change as part of the nature of the Earth - even, or perhaps especially in this age of humans.

\section{Acknowledgements}

I wish to thank my supervisors Gordon Walker and Nils Markusson, two anonymous reviewers, and participants in conferences and seminars at the IBG/RGS in Exeter, 2015; and more recently at the Institute for Advanced Sustainability Studies (IASS) in Potsdam, the Centre for Anthropological, Political and Social Theory at Copenhagen University, and the Seedbox at Linköping University for their helpful comments and feedback. The paper was largely completed during a short residency at IASS in November 2016: thanks are particularly due to Stefan Schafer and Mark Lawrence for facilitating that opportunity. Errors, as ever, remain my responsibility. 


\section{References}

Alano, B. 2008. Untitled message, $4^{\text {th }}$ February.

https://groups.google.com/forum/\#!forum/geoengineering

Baskin, J. 2015. Paradigm Dressed as Epoch: The Ideology of the Anthropocene. Environmental Values, 24(1): 9-29.

Basl, J. 2010. Restitutive Restoration: New Motivations for Ecological Restoration. Environmental Ethics, 32(2): 135-147 doi: 10.5840/enviroethics201032216

Beauchamp T.L. and J.F. Childress, 2008. Principles of Biomedical Ethics. Oxford: Oxford University Press.

Bipartisan Policy Center, 2011. Task Force on Climate Remediation Research Report online at: http://bipartisanpolicy.org/wpcontent/uploads/sites/default/files/BPC\%20Climate\%20Remediation\%20Final\%20Report.pdf

Brewin, Kester. 2012. Mutiny! Why We Love Pirates and How They Can Save Us. London: Vaux / Kester Brewin.

Buck, H.J. 2012. 'Climate Remediation to Address Social Development Challenges: Going Beyond Cost- Benefit and Risk Approaches to Assessing Solar Radiation Management.' In Engineering the Climate: The Ethics of Solar Radiation Management, edited by C.J. Preston, 133-48. Lanham, MD: Rowman and Littlefield.

Burman, P. 1995. A Question of Ethics. Building Conservation. Online at http://www.buildingconservation.com/articles/ethics/conservation_ethics.htm

Cameron, C. 2008. The World Heritage Committee and Authenticity. APT Bulletin, 39(2/3): 19-24, http://www.jstor.org/stable/25433947

Clark, N. 2011. Inhuman Nature: Sociable Life on a Dynamic Planet. London: Sage.

Cotton, M. 2014. Ethics and Technology Assessment: A Participatory Approach. Berlin: Springer Verlag.

DeSilvey, C. 2017. Curated Decay: heritage beyond saving. Minneapolis: University of Minnesota Press.

Eveleth, R 2015a. Blueprint for a better human body. The Atlantic, May $15^{\text {th }}$. Online at: http://www.theatlantic.com/technology/archive/2015/05/a-blueprint-for-a-better-humanbody/389655/

Eveleth, R. 2015b. Repainting the Scar. The Atlantic, August $3^{\text {rd }}$. Online at: http://www.theatlantic.com/health/archive/2015/08/repainting-the-scar-tattoo-skin-graftfirefighter/400064/

Fleming, J. 2010. Fixing the Sky: The Checkered History of Weather and Climate Control. New York, Columbia University Press.

FitzPatrick, W. 'Morality and Evolutionary Biology', The Stanford Encyclopedia of Philosophy (Spring 2016 Edition), E.N. Zalta (ed.. Online at: https://plato.stanford.edu/archives/spr2016/entries/morality-biology/

Fraser, N. and Honneth, A. 2003. Redistribution or recognition? A political-philosophical exchange. London: Verso.

Gade, C.B.N. 2013. Ubuntu and Restorative Justice: Addressing the Strife and Divisions of the Past in Post-Apartheid South Africa. PhD Thesis, Department of Culture and Society, Philosophy Section, Aarhus University. 
Gaiman, N. 2013. Happily Ever After. The Guardian 13 ${ }^{\text {th }}$ October 2007. Online at: https://www.theguardian.com/books/2007/oct/13/film.fiction

Galarraga, M. and Szerszynski, B. 2012. 'Making climates: solar radiation management and the ethics of fabrication.' In Engineering the Climate: The Ethics of Solar Radiation Management, edited by C.J. Preston, 221-35. Lanham, MD: Rowman and Littlefield.

Galinsky, A.D., K. Hugenberg, C. Groom and G. Bodenhausen, 2003. The Reappropriation of Stigmatizing Labels: Implications for Social Identity. Identity Issues in Groups: Research on Managing Groups and Teams, Volume 5, 221-256.

Gardiner, S.M. 2006. A Perfect Moral Storm: Climate Change, Intergenerational Ethics and the Problem of Moral Corruption. Environmental Values 15(3): 397-413.

Gilligan, C. 1982. In A Different Voice. Cambridge, MA: Harvard University Press.

Graham, S. and N. Thrift, 2007. Out of order: understanding repair and maintenance. Theory culture and society 24(3): 1-25.

Groves, C. 2014. Care, Uncertainty and Intergenerational Ethics. London: Palgrave Macmillan.

Hamilton, C. 2017. Defiant Earth: the Fate of Humans in the Anthropocene. Cambridge: Polity.

Held, V. 2006. The Ethics of Care. New York, NY: Oxford University Press.

Higgs, E. 2003. Nature by Design: People, Natural Process and Ecological Restoration. Cambridge MA: MIT Press.

Higgs, E. 2012. 'History, Novelty and Virtue in Ecological Restoration.' In Ethical Adaptation to Climate Change, edited by A. Thompson and J. Bendik-Keymer: 81-102. Cambridge MA: MIT Press.

Hourdequin, M. 2012. 'Geoengineering, solidarity and moral risk.' In Engineering the Climate: The Ethics of Solar Radiation Management, edited by C.J. Preston: 15-32. Lanham, MD: Rowman and Littlefield.

Jackson, S.J. 2014. Rethinking repair. In Media Technologies: Essays on Communication, Materiality, and Society, edited by T. Gillespie, P. J. Boczkowski, and K.A. Foot: 221-239. Cambridge MA: MIT Press.

Juengst, E. and D. Moseley, 'Human Enhancement', The Stanford Encyclopedia of Philosophy (Spring 2016 Edition), E.N. Zalta (ed.) Online at: https://plato.stanford.edu/archives/spr2016/entries/enhancement/

Katz, E. 2002. Understanding moral limits in the duality of artifacts and nature: a reply to critics. Ethics \& the Environment, 7(1): 138-146.

Keith, D. 2013. A Case for Climate Engineering. Cambridge MA: MIT Press/Boston Review Books. Kintish, E. 2010. Hack the Planet. London: Wiley.

Klein, N. 2014. This Changes Everything: Capitalism vs. the Climate. London: Simon \& Schuster.

Lal, R. 2004. Soil Carbon Sequestration Impacts on Global Climate Change and Food Security Science 304(5677): 1623-1627 DOI: 10.1126/science.1097396

Kanchwala, R. 2012. Geoengineering: An Interim Strategy to Curb Global Warming? A Talk With John Latham. Vagabond Journey, December. Online at: http://www.vagabondjourney.com/geoengineering-interim-strategy-curb-global-warming-johnlatham/

Lee, A., A.P. Hermans and B. Hale, 2014. Restoration, Obligation, and the Baseline Problem. Environmental Ethics 36: 171-186. 
Lenton,T.M., H. Held, E. Kriegler, J.W. Hall, W. Lucht, S. Rahmstorf, and H.J. Schellnhuber, 2008. Tipping elements in the Earth's climate system. PNAS 105 (6) 1786-1793; doi:10.1073/pnas.0705414105

Light, A. 2012. 'The death of restoration.' In Ethical Adaptation to Climate Change, edited by A. Thompson and J. Bendik-Keymer, 105-122. Cambridge MA: MIT Press.

Loukkanen, M., S. Huttunen and M. Hildén, 2014. Geoengineering, newsmedia and metaphors: Framing the controversial. Public Understanding of Science 23(8): 966-81. doi:10.1177/0963662513475966

Markusson, N., M.D. Gjefsen, J.C. Stephens and D. Tyfield, 2017. The political economy of technical fixes: The (mis)alignment of clean fossil and political regimes. Energy Research \& Social Science 23: $1-10$

Marris, E. 2011. Rambunctious Garden: Saving Nature in a Post-Wild World. London: Bloomsbury.

Martindale, L. 2015. Understanding humans in the Anthropocene: Finding answers in geoengineering and Transition Towns. Environment and Planning D: Society and Space 33(5) 907924 doi: $10.1177 / 0263775815604914$

McLaren, D. 2012. A comparative global assessment of potential negative emissions technologies. Process Safety and Environmental Protection 90(6): 489-500 doi: 10.1016/j.psep.2012.10.005

McLaren, D. 2016a. 'Framing out justice: the post-politics of climate engineering discourses.' In Climate Justice and Geoengineering: Ethics and Policy in the Atmospheric Anthropocene, edited by C.J. Preston, Chapter 10. London: Rowman and Littlefield.

Mclaren, D. 2016b Mitigation deterrence and the moral hazard in solar radiation management. Earth's Future, doi: 10.1002/2016EF000445

McLaren, D. 2017. Mirror, Mirror. Fairness and Justice in Climate Engineering. PhD thesis, Lancaster University. http://dx.doi.org/10.17635/lancaster/thesis/184

McLaren, D. (forthcoming) Whose Climate? And whose 'justice'? Conceptions of justice in climate engineering modelling (revised version submitted to ERSS).

Middleton, J. 2014. Mending. In Routledge Handbook Of Sustainability And Fashion, edited by K. Fletcher and M. Tham, 262-74. Oxford: Routledge.

Minteer, B.A. and R.E. Manning, 1999. Pragmatism in Environmental Ethics: Democracy, Pluralism, and the Management of Nature. Environmental Ethics 21(2):191-207. doi: 10.5840/enviroethics199921231

Monbiot, G. 2013. Feral. London: Allen Lane.

Moore, J.W. 'Introduction' in Anthropocene Or Capitalocene?: Nature, History, and the Crisis of Capitalism. Oakland: PM Press.

NAS, 2015a. Climate Intervention: Reflecting Sunlight to Cool Earth. Committee on Geoengineering Climate. Washington DC: National Academies Press.

NAS, 2015b. Climate Intervention: Carbon Dioxide Removal and Reliable Sequestration, Committee on Geoengineering Climate. Washington DC: National Academies Press.

Nehrlich, B. and R. Jaspal, 2012. Metaphors we die by? Geoengineering, metaphors and the argument from catastrophe. Metaphor and Symbol, 27(2) 131-147.

Nelleman, C., E. Corcoran, C.M. Duarte, L. Valdes, C. DeYoung, L. Fonseca, G Grimsditch (eds) Blue Carbon. A rapid response assessment. UNEP: GRID-Arendal, www.grida.no 
Nicholas, G.P. and A. Wylie, 2012."'Do Not Do Unto Others...": Cultural Misrecognition and the Harms of Appropriation in an Open-Source World.' In Appropriating the Past: Philosophical Perspectives on Archaeological Practice, edited by R. Coningham and G. Scarre: 195-221. Cambridge: Cambridge University Press.

Nissen, J. 2008. Untitled message. $25^{\text {th }}$ August. Online at: https://groups.google.com/forum/\#!forum/geoengineering

Rancière, J. (translated by S. Corcoran) 2004. Introducing disagreement. Angelaki, 9:3, 3-9. doi: 10.1080/0969725042000307583

Reiner, P.B. 2010. Distinguishing between Restoration and Enhancement in Neuropharmacology. AMA Journal of Ethics 12(11): 885-888.

Royal Society, 2009. Geoengineering the climate: science, governance and uncertainty. London: Royal Society.

Ruddiman, W., S. Vavrus, J. Kutzbach, F. He, 2014. Does pre-industrial warming double the anthropogenic total? The Anthropocene Review, 1(2):147-153.

Sandler, R. 2012. 'Global Warming and Virtues of Ecological Restoration,' in Ethical Adaptation to Climate Change: Human Virtues of the Future, edited by Thompson, A. and Bendik-Kramer, J., 63-80. Cambridge MA: MIT Press.

Sayer, A. 2011. Why Things Matter to People: Social Science, Values and Ethical Life. Cambridge: Cambridge University Press.

Schlosberg, D. 2007. Defining Environmental Justice: Theories, Movements, and Nature. Oxford: Oxford University Press.

Schlosberg, D. 2012. 'Justice, ecological integrity, and climate change.' In Ethical Adaptation to Climate Change, edited by A. Thompson and J. Bendik-Keymer, 165-184. Cambridge MA: MIT Press.

Scott, J.C. 1999. Seeing like a State: How Certain Schemes to Improve the Human Condition Have Failed. New Haven: Yale University Press.

Sennett, R., 2013. Together: The Rituals, Pleasures and Politics of Cooperation. London: Penguin.

Steffen, W., Å. Persson, L. Deutsch, J. Zalasiewicz, M. Williams, K. Richardson, C. Crumley, P. Crutzen, C. Folke, L. Gordon, M. Molina, V. Ramanathan, J. Rockström, M. Scheffer, H.J. Schellnhuber and U. Svedin, 2011. The Anthropocene: From Global Change to Planetary Stewardship. AMBIO 40:739-761, doi: 10.1007/s13280-011-0185-x

Stilgoe, J. 2015. Experiment Earth: Responsible Innovation in Geoengineering. London: Routledge.

Thomas S.C. and Gale, N. 2015. Biochar and forest restoration: a review and meta- analysis of tree growth responses. New Forests 46:931-946 DOI 10.1007/s11056-015-9491-7

Throop 2012. 'Environmental Virtues and the Aims of Restoration,' in Ethical Adaptation to Climate Change: Human Virtues of the Future, edited by Thompson, A. and Bendik-Kramer, J., 27-46.

Cambridge MA: MIT Press.

Tollefson, J. 2012. Ocean-fertilization project off Canada sparks furore. Nature 490 ( $25^{\text {th }}$ October $): 458-$ 9

Tronto, J. 1994. Moral Boundaries: A Political Argument for an Ethic of Care. New York, NY: Routledge.

Verbeek, P.P. 2011. Moralizing Technology: Understanding And Designing The Morality Of Things. Chicago: University of Chicago Press.

Walker, G. 2012. Environmental Justice: Concepts, Evidence and Politics. London: Routledge. 
Table 1: Emergent ethics of repair in five domains

\begin{tabular}{|c|c|c|c|}
\hline & Care & Integrity & Legibility \\
\hline Reconstruction & $\begin{array}{l}\text { Maintenance preferred } \\
\text { to reconstruction. } \\
\text { Individuality of object } \\
\text { and context important. }\end{array}$ & $\begin{array}{l}\text { Interventions should } \\
\text { be reversible, } \\
\text { protecting the historic } \\
\text { integrity of the object. }\end{array}$ & $\begin{array}{l}\text { Ethical interventions } \\
\text { are transparent and } \\
\text { documented, } \\
\text { permitting } \\
\text { reversibility. }\end{array}$ \\
\hline Remediation & $\begin{array}{l}\text { A relationship of care } \\
\text { for the individual } \\
\text { subject is central, with } \\
\text { emphasis on consent } \\
\text { and even active } \\
\text { participation. }\end{array}$ & $\begin{array}{l}\text { Restoring autonomy } \\
\text { and self-directed } \\
\text { functioning. Unease } \\
\text { with enhancement } \\
\text { rather than } \\
\text { remediation. }\end{array}$ & $\begin{array}{l}\text { An emerging (if } \\
\text { minority) cultural } \\
\text { view supports } \\
\text { visibility of } \\
\text { prosthetics and } \\
\text { reconstructive } \\
\text { surgery to demand } \\
\text { recognition. }\end{array}$ \\
\hline Restoration & $\begin{array}{l}\text { Restorers demonstrate } \\
\text { clear attachment to the } \\
\text { systems they work to } \\
\text { restore. }\end{array}$ & $\begin{array}{l}\text { Restoration of self- } \\
\text { directed functioning - } \\
\text { focused on re- } \\
\text { establishing natural } \\
\text { process }\end{array}$ & $\begin{array}{l}\text { Honest narrative of } \\
\text { place, preserving the } \\
\text { 'disturbance memory' } \\
\text { (Light, 2012) }\end{array}$ \\
\hline Reconfiguration & $\begin{array}{l}\text { The artist recovers or } \\
\text { rehabilitates cultural } \\
\text { material, which is a } \\
\text { subject of their care }\end{array}$ & $\begin{array}{l}\text { Integrity is more } \\
\text { about the artistic } \\
\text { process, than about } \\
\text { authenticity to the } \\
\text { source. }\end{array}$ & $\begin{array}{l}\text { Respect for and } \\
\text { acknowledgement of } \\
\text { cultural sources, } \\
\text { creating narrative } \\
\text { fidelity }\end{array}$ \\
\hline Reconciliation & $\begin{array}{l}\text { Care for the } \\
\text { relationships between } \\
\text { individuals or within } \\
\text { functioning } \\
\text { communities is central } \\
\text { to reconciliation }\end{array}$ & $\begin{array}{l}\text { Aims to restore or re- } \\
\text { establish the integrity } \\
\text { of the damaged } \\
\text { community or } \\
\text { relationship }\end{array}$ & $\begin{array}{l}\text { Demands honesty } \\
\text { about the harms that } \\
\text { were done: no } \\
\text { pretense or covering } \\
\text { up. Narrative fidelity } \\
\text { is clear. }\end{array}$ \\
\hline
\end{tabular}

